\title{
Safety and Efficacy of Laparoscopic Appendectomy in Pregnant Females
}

\author{
Mohamed F Amin ${ }^{1}$, Morsi M Morsi ${ }^{2}$, Mostafa M Elaidy ${ }^{3}$, Mohamed S Badr $^{4}$, Ahmed M Farag 5 , Safaa A Ibrahim ${ }^{6}$
}

\begin{abstract}
Introduction: Laparoscopic surgery during pregnancy is contraindicated absolutely or relatively through the last decade; however, laparoscopic appendectomy (LA) is still performed in pregnant women.

Materials and methods: Thirty-one pregnant females with a diagnosis of acute appendicitis and managed with LA or OA in the emergency unit of the department of general surgery from June 2015 to December 2017.

Results: Eighteen patients underwent LA, while 13 patients underwent OA. No difference was noticed between both groups regarding the operative duration, and fetal and maternal outcomes. However, the group of LA had faster first flatus and shorter inpatient duration than the OA group.

Conclusion: Laparoscopic appendectomy is distinguished with efficacy and safety procedure throughout pregnancy and should be considered a good replacement for open appendectomy.

Keywords: Appendectomy, Appendix, Laparoscopy, Pregnancy.

World Journal of Laparoscopic Surgery (2018): 10.5005/jp-journals-10033-1354
\end{abstract}

\section{INTRODUCTION}

Abdominal pain during pregnancy can be caused by variant obstetric and nonobstetric pathologies that made diagnosing of acute appendicitis during pregnancy quite a challenging problem. Limitations of CT scanning, physiological and anatomical changes during pregnancy like physiological leukocytosis that could be associated with pregnancy were also contributing factors for difficult diagnosis. ${ }^{1}$

Acute appendicitis is the most common nonobstetric condition requiring urgent surgical interference during pregnancy, with an estimated incidence between $0.05 \%$ and $0.13 \% .^{2}$

The rate of complicated appendicitis is much higher in pregnant women. ${ }^{3}$ Delay in diagnosis increases the peril of complications to the mother and fetus when acute appendicitis is suspected and an aggressive approach is recommended. ${ }^{4}$

Laparoscopic appendectomy during pregnancy is recommended in the first and second trimesters. Regarding the third trimester, there are no clear guidelines for performing laparoscopic appendectomy. ${ }^{5}$ The advantages of laparoscopic appendectomy over open appendectomy include less postoperative pain, early discharge, less risk for wound infection, and giving feasibility for laparoscopic abdominal exploration. ${ }^{1,6}$

In this study, we assessed the safety and efficacy of laparoscopic appendectomy in pregnant females.

\section{Materials and Methods}

This retrospective was carried out in the emergency unit of the General Surgery Department, Zagazig University from June 2015 to December 2017. Thirty-one pregnant women were included in the study. All of them were suffering from abdominal pain in the right lower quadrant with or without fever, suggesting acute appendicitis. All patients underwent perioperative obstetric consultation and fetal monitoring. Complete blood count and pelviabdominal ultrasound were carried out to confirm the diagnosis and

\begin{abstract}
${ }^{1-3}$ Department of General Surgery, Zagazig University, Zagazig, Ash Sharqia Governorate, Egypt

${ }^{4-6}$ Department of Obstetrics and Gynecology, Zagazig University, Zagazig, Ash Sharqia Governorate, Egypt

Corresponding Author: Mohamed F Amin, Department of General Surgery, Zagazig University, Zagazig, Ash Sharqia Governorate, Egypt, Phone: +20 1006255621, e-mail: dr_ruaa2000@yahoo.com

How to cite this article: Amin MF, Morsi MM, et al. Safety and Efficacy of Laparoscopic Appendectomy in Pregnant Females. World J Lap Surg 2018;11(3):128-131.
\end{abstract}

Source of support: Zagazig University

Conflict of interest: None

assess pregnancy. All preoperative data including age, history of previous section, gestation age at operation, and accuracy of the diagnostic U/S were recorded. Also, all operative data including the surgery duration, return time to normal bowel movement, inpatient length, postoperative complications, and final pathology were recorded. Obstetric and fetal data including the incidence of preterm labor, delivery type, and fetal mortality were also recorded.

\section{Laparoscopic Appendectomy Technique in Pregnant Females}

The procedure was done in the supine position with a slight tilt to the left side $\left(20-30^{\circ}\right)$. The procedure was done under general anesthesia with maintained continuous end tidal volume $\mathrm{CO}_{2}$ monitoring. Insertion of a Foley catheter was also done along with application of pneumatic compression devices on the legs. A prophylactic antibiotic was administrated. Also, prophylactic tocolysis was administrated. We performed the operation by insertion of three ports. The first one, a supraumbilical $10 \mathrm{~mm}$ port according to the size of the uterus $(3-4 \mathrm{~cm}$ above the uterine 


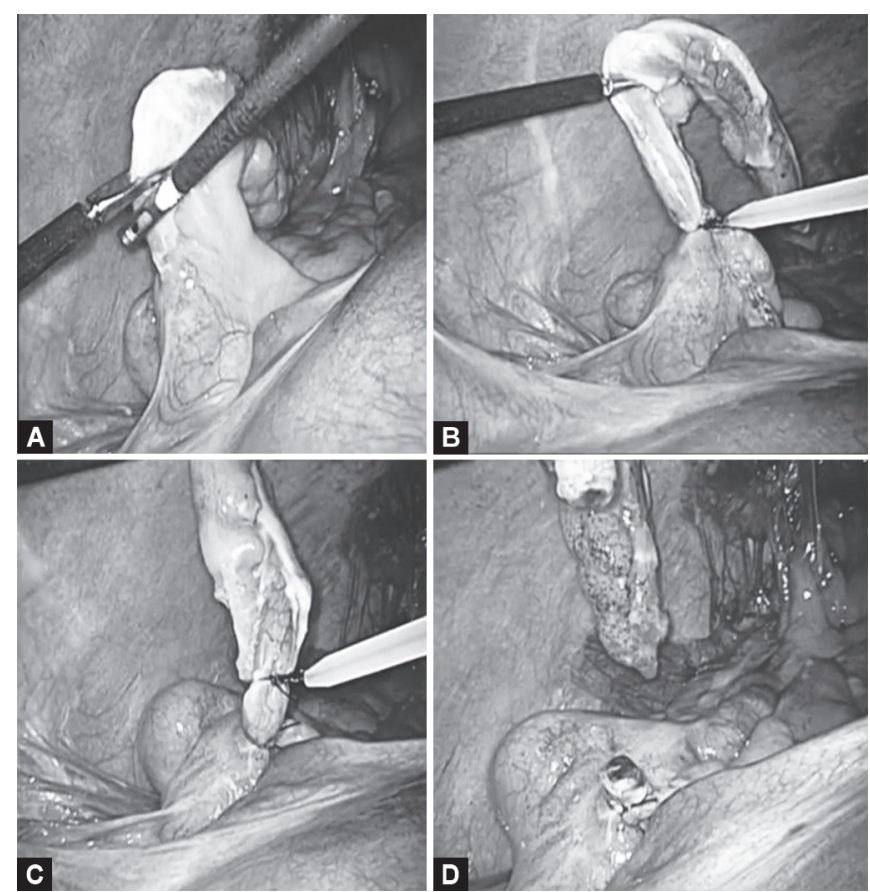

Figs 1 A to D: Laparoscopic appendectomy in pregnant female. (A) Elevation of the appendix with 27 weeks gravid uterus; (B) Ligation of complicated appendix using endo-loop after devascularization of mesoappendix; (C) Ligation of the appendix using endo-loop; (D) Appendiceal stump after ligation of the appendix

fundus) for the camera, was inserted by open method (HASSON method) to avoid injury to the uterus. Another two working $5 \mathrm{~mm}$ ports were inserted on both sides depending on the gestation age. Pneumoperitoneum by $\mathrm{CO}_{2}$ was adjusted to be $(10-12 \mathrm{~mm} \mathrm{Hg})$.The appendix was elevated and the mesoappendix was divided using the bipolar diathermy or harmonic scalpel. The appendiceal stump was ligated using endo-loop or intracorporeal stitches. Retrieval of the appendix in a glove was done through the umbilical port site (Fig. 1). A drain was inserted to be removed after 1-2 days postoperative.

\section{Statistical Analysis}

Data are presented as means \pm standard deviations. Groups were compared using the Mann-Whitney $U$ test or $\chi^{2}$ test, as appropriate. SPSS version 14.0 for Windows was used for all statistical comparisons, and we considered results to be significant at $p<0.05$.

\section{Results}

Thirty-one pregnant patients were selected for our study. Eighteen patients underwent laparoscopicappendectomy (LA), while thirteen patients had an open appendectomy (OA). The mean age of the LA group was $26 \pm 2.8$ years and that of the OA group was $29.2 \pm 3.2$ years. There were no significant differences in the BMI or the gestation age at operation between the two groups. Regarding all patients, seven patients ( $4 \mathrm{LA}$ and $3 \mathrm{OA}$ ) were in the 1st trimester, 16 patients ( $11 \mathrm{LA}$ and $5 \mathrm{OA}$ ) were in the 2 nd trimester, and eight patients ( $3 \mathrm{LA}$ and $5 \mathrm{OA}$ ) were in the 3rd trimester. In all patients, preoperative ultrasound was done with a false positive rate $(16.13 \%)$ and a false negative rate (12.9\%) for all patients (Table 1$)$.
Table 1: Preoperative demographic and clinical data

\begin{tabular}{llll}
\hline Perioperative data & LA (18 patients) & OA (13 patients) & p value \\
\hline Age & $\begin{array}{l}18-29(26 \pm 2.8) \\
\text { years }\end{array}$ & $\begin{array}{l}23-35(29.2 \pm 3.2) \\
\text { years }\end{array}$ & $0.7^{*}$ \\
BMI & $23.4 \pm 3.1$ & $23.1 \pm 2.8$ & $0.366^{*}$ \\
$\begin{array}{l}\text { Gestation age at } \\
\text { operation }\end{array}$ & $18.4 \pm 6.2$ weeks & $18.6 \pm 5.4$ weeks & $0.317^{*}$ \\
1st trimester & $4(22.22 \%)$ & $3(23.08 \%)$ & $0.342^{* *}$ \\
2nd trimester & $11(61.11 \%)$ & $5(38.46 \%)$ & \\
3rd trimester & $3(16.67 \%)$ & $5(38.46 \%)$ & \\
Previous CS & $4(22.22 \%)$ & $7(53.85 \%)$ & $0.069^{* *}$ \\
Preoperative U/S & $18(100 \%)$ & $13(100 \%)$ & $0.764^{* *}$ \\
False-positive & $2(11.11 \%)$ & $3(23.08 \%)$ & \\
False-negative & $2(11.11 \%)$ & $2(15.38 \%)$ & \\
\hline
\end{tabular}

${ }^{*} t$ test $p$ value

${ }^{* *}$ Chi-square test $p$ value

Table 2: The final histopathological diagnosis after operation

\begin{tabular}{|c|c|c|c|c|}
\hline Trimester & Final histopathology & $\begin{array}{l}\text { LA (18 } \\
\text { patients) }\end{array}$ & $\begin{array}{l}\text { OA (13 } \\
\text { patients) }\end{array}$ & $\begin{array}{l}X^{2} \\
p \text { value }\end{array}$ \\
\hline \multirow[t]{3}{*}{ 1st trimester } & Normal appendix & 0 & 0 & 1 \\
\hline & $\begin{array}{l}\text { Acute suppurative } \\
\text { appendix }\end{array}$ & 3 & 2 & \\
\hline & $\begin{array}{l}\text { Complicated } \\
\text { appendix }\end{array}$ & 1 & 1 & \\
\hline \multirow[t]{3}{*}{ 2nd trimester } & Normal appendix & 1 & 2 & 0.338 \\
\hline & $\begin{array}{l}\text { Acute suppurative } \\
\text { appendix }\end{array}$ & 7 & 2 & \\
\hline & $\begin{array}{l}\text { Complicated } \\
\text { appendix }\end{array}$ & 3 & 1 & \\
\hline \multirow[t]{3}{*}{ 3rd trimester } & Normal appendix & 1 & 1 & 1 \\
\hline & $\begin{array}{l}\text { Acute suppurative } \\
\text { appendix }\end{array}$ & 0 & 2 & \\
\hline & $\begin{array}{l}\text { Complicated } \\
\text { appendix }\end{array}$ & 2 & 2 & \\
\hline
\end{tabular}

Regarding the final histopathology of the appendix, in the laparoscopic cases normal appendix was presented in two patients, acute suppurative in ten cases, while complicated appendix was presented in six cases. In open cases, normal appendix was presented in three patients, acute suppurative in six cases, while complicated appendix was presented in four cases (Table 2).

The duration of surgery in LA in this study was $40 \pm 18.4$ minutes, and in the OA was $45 \pm 15.6$ minutes. The time of the first flatus and the time of starting oral fluid were earlier in LA. Postoperative complications occurred in three patients. One patient developed intra-abdominal abscess two weeks after a laparoscopic appendectomy. She was 25 years old with gestation age of 25 weeks, was treated with application of US-guided pigtail, and antibiotics. She completed her pregnancy and delivered a healthy male baby by C.S. Two patients developed wound infection after an open appendectomy, and it was managed with repeated dressing and antibiotics (Table 3).

In our study, there was no mortality and all patients had uncomplicated deliveries. One patient had a preterm labor of a healthy female baby that entered the incubator for two weeks and discharged without comorbidity. The two groups had the same results regarding the fetal outcomes with no problems or morbidity (Table 4). 
Table 3: Operative outcomes of laparoscopic and open appendectomy during pregnancy

\begin{tabular}{llll}
\hline Outcomes & LA (18 patients) & OA (13 patients) & $p$ value \\
\hline $\begin{array}{l}\text { Operative } \\
\text { duration }\end{array}$ & $40 \pm 18.4$ minutes & $45 \pm 15.6$ minutes & $0.284^{*}$ \\
Time to 1st flatus & $1.4 \pm 0.5$ days & $2.7 \pm 1.2$ days & $1^{*}$ \\
Time to oral fluid & $2.2 \pm 0.4$ days & $4.1 \pm 1.9$ days & $1^{*}$ \\
$\begin{array}{l}\text { Length of } \\
\text { hospital stay }\end{array}$ & $3.2 \pm 1.8$ days & $5.9 \pm 2.6$ days & $0.9^{*}$ \\
Complications & 1 (pelvic abscess) & 2 (wound infection) & $0.361^{* *}$ \\
\hline
\end{tabular}

${ }^{*} t$ test $p$ value

${ }^{* *}$ Chi-square test $p$ value

Table 4: Obstetric outcomes of laparoscopic and open appendectomy during pregnancy

\begin{tabular}{llll}
\hline Outcomes & LA (18 patients) & OA (13 patients) & $\begin{array}{l}X^{2} p \\
\text { value }\end{array}$ \\
\hline Preterm labor & $1(5.56 \%)$ & 0 & 1 \\
CS delivery & $13(72.22 \%)$ & $9(69.23 \%)$ & 0.856 \\
Vaginal delivery & $5(27.78 \%)$ & $4(30.77 \%)$ & 0.856 \\
\hline
\end{tabular}

\section{Discussion}

The most common abdominal surgery during pregnancy for nonobstetric causes is acute appendicitis, and its incidence is similar to that in nonpregnant women; the diagnosis is difficult because of the physiologic and anatomic changes that occur during pregnancy. ${ }^{8}$ The risk for appendicitis does not appear to be increased by pregnancy, but the incidence of perforated appendicitis in pregnant women is much higher than in the general population. ${ }^{3}$ Complicated appendicitis can lead to maternal and fetal morbidity and even fetal loss, so pregnant women should undergo immediate surgery when appendicitis is suspected, regardless of the gestation age of the fetus. ${ }^{9}$

Acute appendicitis can present at any trimester but half of the cases can be seen at the 2nd trimester, an observation published by Kapan et al. In our study, more than half of the cases were presented in the 2 nd trimester. But in a study by Kazar et al. and Mazze et al., they observed that the most accurate diagnosis for acute appendicitis was during the first trimester. ${ }^{10,11}$

It was known that the change in the physiology and the anatomy during pregnancy made the diagnosis of acute appendicitis more difficult in pregnant women. ${ }^{7}$ The number of negative laparoscopic and open exploration rates during pregnancy ranges from $0 \%$ to $50 \%$ and $15 \%$ to $50 \%$, respectively. ${ }^{1}$ In our study, the negative appendectomy rate was $16.13 \%$ (five patients) and it was $11.11 \%$ (two patients) in LA and $23.08 \%$ (three patients) in OA. In a study by Jun Chul et al., the overall negative appendectomy rate was $9.8 \%$ (9.1\% for the LA group and $10.3 \%$ for the OA group). ${ }^{7}$

In our study, there was no conversion of laparoscopic to open because the operation is done by a highly experienced laparoscopic surgeon. Walsh et al. reported $1 \%$ as the rate of conversion of laparoscopic to open appendectomy. In this study, none of our procedures converted from laparoscopic to open appendectomy. ${ }^{12}$

Diagnostic imaging studies are often used to clarify a confusing clinical picture. Ultrasonography is widely used as a first-line diagnostic test because of its safety for the mother and fetus and its relatively high sensitivity and specificity for many intraabdominal processes. In our study, U/S was done in all patients; acute appendicitis was found in $77.78 \%$ (14 patients) in LA, and was found in $69.23 \%$ (nine patients) in OA. In a study by Chung et al., acute appendicitis was found in 15 (68.2\%) patients in the LA group and $28(71.8 \%)$ in the OA group. ${ }^{7}$

In the last decades, the treatment of choice for acute appendicitis during pregnancy was open appendectomy. But recently, laparoscopic appendectomy could be done in pregnant women with good maternal and fetal outcomes. ${ }^{13}$ Our study supported the safety of LA; the outcomes of LA and OA were the same. Moreover, some proven advantages of $L A$, including better intraoperative visualization, decreased surgical trauma, decreased gravid uterine manipulation, shorter postoperative hospital stay, and faster return to work, maybe even more important in pregnant women. ${ }^{14}$ In our study, the LA group had an earlier recovery of bowel function and shorter hospital stay.

Guidelines for laparoscopic procedures during pregnancy have previously been published by the Society of American Gastrointestinal and Endoscopic Surgeons (SAGES) ${ }^{15}$ and modifications were proposed by Moreno-Sanz et al. ${ }^{16} \mathrm{~A}$ pneumoperitoneum pressure of $10-12 \mathrm{~mm} \mathrm{Hg}$ is recommended as previous animal studies have demonstrated fetal hypercapnia and acidosis secondary to $\mathrm{CO}_{2}$ pneumoperitoneum in pregnant females. ${ }^{15}$ In our study, pneumoperitoneum was adjusted to 10-12 $\mathrm{mm} \mathrm{Hg}$ throughout the duration of the operation.

It has been recommended to position the patient on her left side during surgery to prevent uterine compression of the inferior vena cava and to facilitate access to the appendix. ${ }^{17}$ Morrell and colleagues ${ }^{18}$ have suggested a lateral rotation of the operating table to displace the uterus for better venous return. In our study, all patients were placed in a supine position with a slight left side tilt $\left(20-30^{\circ}\right)$.

One of the most important concerns during LA in pregnancy is the potential risk of injury to the gravid uterus during ports insertion. The Veress needle or the Hasson open technique can be used to gain initial abdominal access. Even though complications have been described for all methods, spontaneous puncture of the uterus with a Veress needle is the most serious. ${ }^{19}$ Friedman and colleagues ${ }^{20}$ reported results in a young pregnant woman at 21 weeks' gestation who underwent LA for suspected appendicitis. Injury to the serosa of the gravid uterus with the Veress needle resulted in postoperative pneumoamnion with subsequent fetal loss. In our study, we insert the camera port supraumbilical 3-4 cm above the uterine fundus with open method (HASSON method) according to the SAGES guidelines for laparoscopy during pregnancy. ${ }^{15}$

Stasis of blood in the lower limbs is common during pregnancy, so pregnant women are at high risk of thromboembolic complications. According to the SAGES guidelines, pneumatic compression devices were recommended to be used during intraoperative and postoperative periods with early postoperative ambulation to prevent deep vein thrombosis in pregnant patients, ${ }^{15}$ and this was applied in the study with no postoperative thromboembolic complications.

The risk of preterm labors with any operative interference during pregnancy was reported to be $10-15 \%$. The same was observed after laparoscopic or open appendectomies that were reported by Kazar and Roslyn. ${ }^{10}$ The overall rate of preterm labors was one patient (3.22\%) in LA.

In conclusion, laparoscopic appendectomy is distinguished by safety and efficacy throughout pregnancy and associated with good maternal and fetal outcomes, similar to those of open appendectomy. In addition to all the advantages of laparoscopy, LA 
is associated with shorter postoperative stay, earlier restoration of bowel function, and low incidence of trauma to the gravid uterus.

\section{References}

1. Pearl J, Price R, et al. Guidelines for diagnosis, treatment, and use of laparoscopy for surgical problems during pregnancy. Surg Endosc 2011;25:3479-3492. DOI: 10.1007/s00464-011-1927-3.

2. Kirshtein B, Perry ZH, et al. Safety of laparoscopic appendectomy during pregnancy. World J Surg 2009;33:475-480. DOI: 10.1007/ s00268-008-9890-4.

3. Corneille MG, Gallup TM, et al. The use of laparoscopic surgery in pregnancy: evaluation of safety and efficacy. Am J Surg 2010;200(3): 363-367. DOI: 10.1016/j.amjsurg.2009.09.022.

4. McGory ML, Zingmond DS, et al. Negative appendectomy in pregnant women is associated with a substantial risk of fetal loss. J Am Coll Surg 2007;205(4):534-540. DOI: 10.1016/j.jamcollsurg.2007.05.025.

5. Samardizic J, Delibegovic S, et al. Laparoscopic appendectomy is safe procedure in the pregnant patients in second trimester. Med Arch 2011;65:125-126.

6. Mazze RI, Kallen B. Appendectomy during pregnancy: a Swedish registry study of 778 cases. Obstet Gynecol 1991;77(6):835-840.

7. Chung JC, Cho GS, et al. Clinical outcomes compared between laparoscopic and open appendectomy in pregnant women. Can J Surg 2013 Oct;56(5):341-346. DOI: 10.1503/cjs.022112.

8. Moreno-Sanz C, Pascual-Pedreño A, et al. Laparoscopic appendectomy during pregnancy: between personal experiences and scientific evidence. J Am Coll Surg 2007;205(1):37-42. DOI: 10.1016/ j.jamcollsurg.2007.01.068.

9. Carver TW, Antevil J, et al. Appendectomy during early pregnancy: What is the preferred surgical approach? Am Surg 2005;71(10):809-812.
10. Kazar RA, Roslyn JJ. The appendix. In: Schwartz SI, Shires GT, et al. ed. Principles of Surgery. USA: McGraw-Hill; 1999. p. 1384e94.

11. Mazze Richard I, BengtK. Appendectomy during pregnancy:a Swedish registry study of 778 cases. Obstet Gynecol 1991;77(6):835e40.

12. Walsh CA, Tang $\mathrm{T}$, et al. Laparoscopic vs open appendectomy in pregnancy: a systematic review. Int J Surg 2008;6(4):339-444. DOI: 10.1016/j.ijsu.2008.01.006.

13. Park SH, Park MI, et al. Laparoscopic appendectomy performed during pregnancy by gynecological laparoscopists. Eur J Obstet Gynecol Reprod Biol 2010;148(1):44-48. DOI: 10.1016/j.ejogrb.2009. 09.026

14. Lyass S, Pikarsky A, et al. Is laparoscopic appendectomy safe in pregnant women? Surg Endosc 2001;15(4):377-379. DOI: 10.1007/ s004640000368.

15. Guidelines for laparoscopic surgery during pregnancy. Society of American Gastrointestinal Endoscopic Surgeons (SAGES). Surg Endosc 1998;12(2):189-190. DOI: 10.1007/s004649900629.

16. Moreno-SanzC,Pascual-Pedreno A, etal.Laparoscopicappendectomy during pregnancy: between personal experiences and scientific evidence. J Am Coll Surg 2007;205(1):37-42. DOI: 10.1016/ j.jamcollsurg.2007.01.068.

17. Curet MJ, Allen D, et al. Laparoscopy during pregnancy. Arch Surg 1996;131:546-550. DOI: 10.1001/archsurg.1996.01430170092017.

18. Morrell DG, Mullins JR, et al. Laparoscopic cholecystectomy during pregnancy in symptomatic patients. Surgery 1992;112(5):856-859.

19. Friedman JD, Ramsey PS, et al. Pneumoamnion and pregnancy loss after second-trimester laparoscopic surgery. Obstet Gynecol 2002;99(3):512-513. DOI: 10.1016/S0029-7844(01)01664-7.

20. Malangoni MA. Gastrointestinal surgery and pregnancy. Gastroenterol Clin North Am 2003;32(1):181-200. DOI: 10.1016/S0889-8553(02) 00072-9. 